\title{
Latest Developments in Composite Materials
}

\author{
Lakhwinder Singh $^{1}$, Geetesh Goga ${ }^{2}$, Mukesh Kumar Rathi ${ }^{3}$ \\ ${ }_{1,2,3}$ (Deptt. Of Mechanical Engineering,K.C.College of Engineering and Technology)
}

\begin{abstract}
The importance of materials in modern world can be realized from the fact that much of the research is being done to apply new materials to different components. However it is natural for a design engineer to rely on trusted and tested materials, but now the world is changing .Today composite materials have changed all the material engineering. The evolution of composite materials has given an opportunity to various designers to use new and better materials resulting in cost reduction, increase in efficiency and better utilization of available resources. Composite materials are finding their applications in aerospace industry, automobile sector, manufacturing industries etc. This paper focuses on the importance of composite materials in mechanical engineering, terminology used in composite materials, various definitions, classification and the latest developments in composite materials in different parts of the world.
\end{abstract}

Keywords: - Aerospace industry, automobile sector, composite materials, latest developments, research

\section{Introduction}

This paper introduces basic concepts of stiffness and strength underlying the mechanics of fiberreinforced advanced composite materials. This aspect of composite materials technology is sometimes termed "micromechanics"because it deals with the relations between macroscopic engineering properties and the microscopic distribution of the material's constituents, namely the volume fraction of fiber. This paper will deal primarily with unidirectionally-reinforced continuous fiber composites, and with properties measured along and transverse to the fiber direction.

\subsection{Materials}

The term composite could mean almost anything if taken at face value, since all materials are composed of dissimilar subunits if examined at close enough detail. But in modern materials engineering, the term usually refers to a "matrix" material that is reinforced with fibres. For instance, the term "FRP" (Fiber Reinforced Plastic) usually indicates a thermosetting polyester matrix containing glass fibres, and this particular composite has the lion's share of today's commercial market. Fig. 1 shows a laminate fabricated by "crossplying" unidirectionally reinforced layers in a $0-90^{\circ}$ stacking sequence.

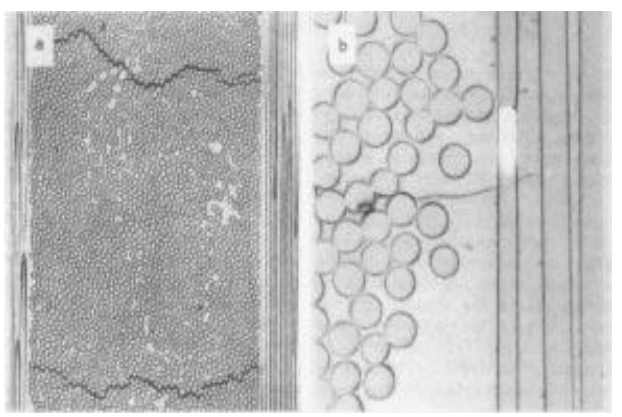

Fig. 1: A crossplied FRP laminate, showing non uniform fiber packing and microcracking (from Harris, 1986).

Many composites used today are at the leading edge of materials technology, with performance and costs appropriate to ultra demanding applications such as spacecraft. But heterogeneous materials combining the best aspects of dissimilar constituents have been used by nature for millions of years. Ancient society, imitating nature, used this approach as well: the Book of Exodus speaks of using straw to reinforce mud in brick making, without which the bricks would have almost no strength. 
Table 1: Properties of Composite Reinforcing Fibers.

\begin{tabular}{|c|c|c|c|c|c|c|c|}
\hline \multirow[t]{2}{*}{ Material } & \multirow{2}{*}{$\begin{array}{l}\mathrm{E} \\
(\mathrm{GPa})\end{array}$} & \multirow{2}{*}{$\begin{array}{l}\sigma \mathrm{b} \\
(\mathrm{GPa})\end{array}$} & $\varepsilon b$ & $\mathrm{P}$ & $E / \rho$ & $\sigma \mathrm{b} / \rho$ & Cost \\
\hline & & & $(\%)$ & $\left(\mathrm{Mg} / \mathrm{m}^{3}\right)$ & $(\mathrm{MJ} / \mathrm{kg})$ & $(\mathrm{MJ} / \mathrm{kg})$ & (Rs/kg) \\
\hline E-Glass & 72.4 & 2.4 & 2.6 & 2.54 & 28.5 & 0.95 & 61.6 \\
\hline S-Glass & 85.5 & 4.5 & 2.0 & 2.49 & 34.3 & 1.8 & $1232-1848$ \\
\hline Aramid & 124 & 3.6 & 2.3 & 1.45 & 86 & 2.5 & $1232-1848$ \\
\hline Boron & 400 & 3.5 & 1.0 & 2.45 & 163 & 1.43 & $18480-24640$ \\
\hline HS Graphite & 253 & 4.5 & 1.1 & 1.80 & 140 & 2.5 & $3696-6160$ \\
\hline HM Graphite & 520 & 2.4 & 0.6 & 1.85 & 281 & 1.3 & $12320-36960$ \\
\hline
\end{tabular}

As seen in Table 1,[1] the fibers used in modern composites have strengths and stiffnesses far above those of traditional bulk materials. The high strengths of the glass fibers are due to processing that avoids the internal or surface flaws which normally weaken glass, and the strength and stiffness of the polymeric aramid fiber is a consequence of the nearly perfect alignment of the molecular chains with the fiber axis.

Of course, these materials are not generally usable as fibers alone, and typically they are impregnated by a matrix material that acts to transfer loads to the fibers, and also to protect the fibers from abrasion and environmental attack. The matrix dilutes the properties to some degree, but even so very high specific (weightadjusted) properties are available from these materials. Metal and glass are available as matrix materials, but these are currently very expensive and largely restricted to R\&D laboratories. Polymers are much more commonly used, with unsaturated styrene-hardened polyesters having the majority of low-to-medium performance applications and epoxy or more sophisticated thermosets having the higher end of the market. Thermoplastic matrix composites are increasingly attractive materials, with processing difficulties being perhaps their principal limitation.

\subsection{Terminology and Basic Properties:}

Composites are being commercialized in three major fields: polymer-matrix composites (PMCs), metal-matrix composites (MMCs), and ceramic-matrix composites (CMCs).Other classification schemes based on a matrix/fibre notation., such as $\mathrm{Al} / \mathrm{SiCand} 6061 / \mathrm{SiC} / 40$ p-T6 for aluminium reinforced with silicon carbide and boron- and carbon-fibre reinforced polymers (BFRP or CFRP), are also being used. The recognition of the three basic types of composites (PMCs ,MMCs , and CMCs)is based on the nature of the matrix material. Each of these types may make use of particle or either discontinuous (short fibre) or continuous fibre reinforcement for property enhancement. It must be realized that systems reinforced with particulate, discontinuous, and continuous fibres give rise to different physical and mechanical properties, and that they must be utilized accordingly.

Particulate-reinforced systems can be divided into two categories: dispersion-strengthened, and particle strengthened or particle-reinforced systems. In dispersion strengthened systems, small particles ( $\Phi$ between 0.01 and $0.1 \mu \mathrm{m})$ are dispersed in the matrix that acts as the major load-bearing constituent. In particle-strengthened composites, larger particles $(\Phi>0.1 \mu \mathrm{m})$ are incorporated in the matrix and the load is shared by the matrix and the particles.

To determine the physical and mechanical properties of composites, use is made of expressions known as mixture rules. The density $\rho_{\mathrm{m}}$ of a composite, for example,consisting of particles evenly dispersed in a matrix, is given by [2]

$\rho_{\mathrm{m}}=\mathrm{f}_{1} \rho_{1}+\mathrm{f}_{2} \rho_{2}+\mathrm{f}_{3} \rho_{3}+\ldots \ldots \ldots . . . \mathrm{f}_{\mathrm{i}} \rho_{\mathrm{i}}$

where $\rho_{\mathrm{i}}$ refers to the density, and $\mathrm{f}_{\mathrm{i}}$ to the volume fraction of the individual components $i$. In these systems, the reinforcing particles actually impede slip, thus increasing resistance to plastic deformation of the matrix, which is the main load carrying constituent. Mixture rules for the dispersed phases of spherical particles can be applied even to irregularly shaped or plate like particles, provided the orientation is completely random and the aspect ratio (length to width) is relatively low.

\subsection{Fibres}

The primary function of the reinforcement in composites reinforced with continuous fibres is to provide strength and stiffness and to support the structural load. The purpose of the matrix is to provide shape and form, to protect the fibres from structural damage and adverse chemical attack, to distribute stress, and to provide toughness. The matrix also stabilizes the composite against buckling in compressive loading situations. Fibres, also known as filaments, have finite lengths of at least 100 times their diameter, and are prepared by drawing from a molten bath, by spinning, or by chemical vapour deposition on a substrate such as tungsten or carbon. They are grouped into bundles or strands of 500 to 12000 filaments. The bundles or strands may be chopped 
into short fibres, (for example, in the fabrication of mats) or twisted into yarns suitable for the weaving of fabrics or three dimensional preforms, using a variety of weaving patterns. The strands may be further combined to form tows, with as many as 40000 to 300000 filaments each. Woven fabrics and tows can be processed into chopped fabric squares or chopped fibre tows. In the plain-weave pattern, yarns are interlaced in alternating fashion over and under every other yarn to provide maximum fabric stability and firmness, and minimum yarn slippage. At the time of their formation, the fibres or yarns are sized (with, for example, PVA, glycerol, or polyurethane), to protect the surface and aid the process of further handling such as weaving. Before the fibres are finally used in the fabrication of a composite, the size is usually removed by heat cleaning or washing. For PMCs and MMCs, fibres are now also available pre-impregnated with matrix material in the uncured state. Either continuous or chopped fibre prepregs, available in a variety of dimensions, are supplied to part fabricators to free the user from having to develop, for instance, resin formulations and impregnate fibres. Material can be bought with a resin content and type of fibre made to order. Typical curing conditions can range from a few minutes in a press to several hours in an autoclave.

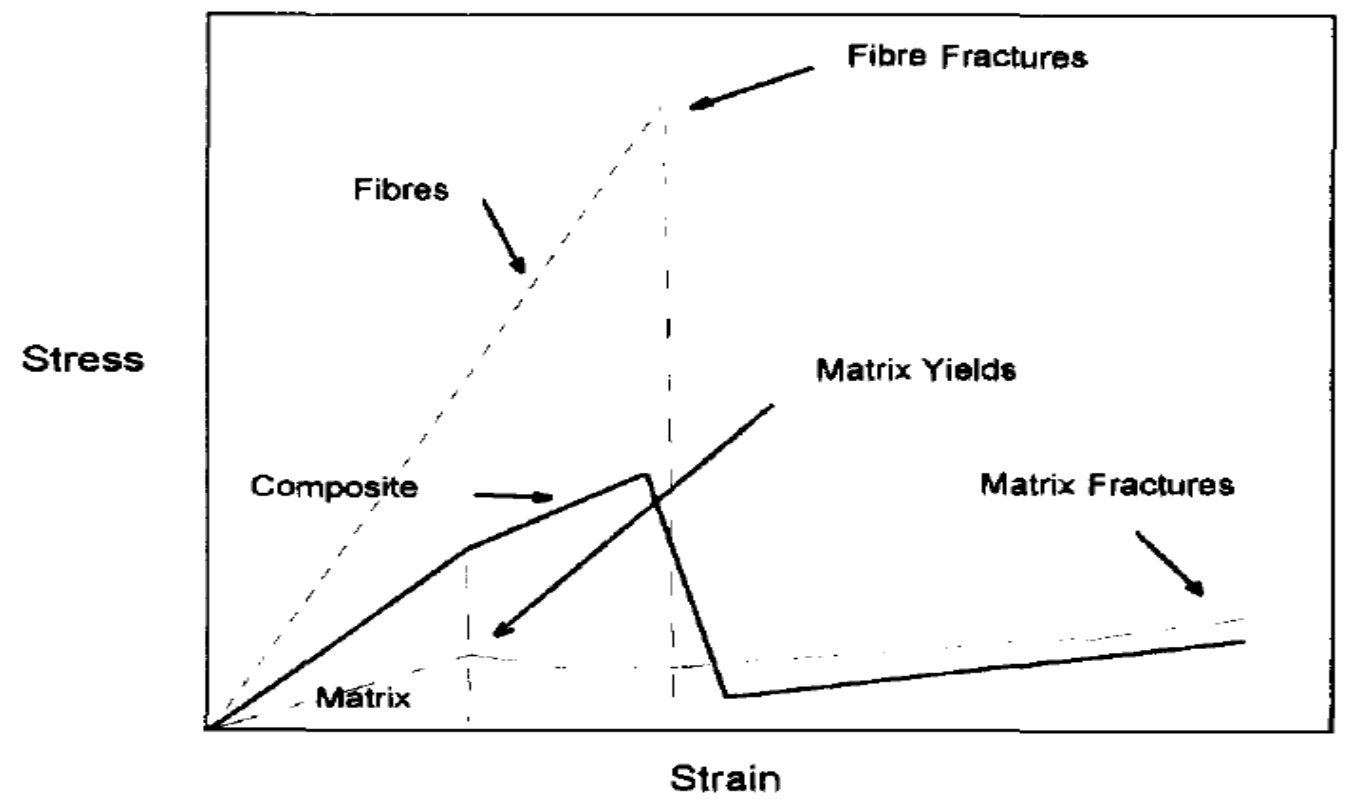

Fig.2. Schematic stress-strain curve for composites reinforced with Continuous fibres

Fibres are also now becoming available as mixtures. An advanced producer of composites, Textron Speciality Materials (TSM), has started to market a continuous-fibre epoxy resin prepreg tape that contains a mixture of large boron fibres and smaller-diameter carbon fibres, with a fibre density of 70 to 80 per cent. While carbon is good in tension, it lacks good compressive properties. This deficiency is overcome through the use of boron fibres that exhibit their best properties in compression. The combined material has good flexural properties, which are of importance to the manufacturing of submersible structures, sporting goods, and medical equipment [4]

A wide variety of reinforcing material is available, ranging from synthetic organic fibres, which offer low densities and high strength but low stiffness, to synthetic inorganic fibres (glass, $\mathrm{SiO}_{2} \mathrm{~B}, \mathrm{C}, \mathrm{ZrO}_{2}$, $\mathrm{Al}_{2} \mathrm{O}_{3}, \mathrm{SiC}$, and $\mathrm{Si}_{3} \mathrm{~N}_{4}$ ), of which glass outstrips the others primarily owing to its lower cost. SiC-whiskers, potentially the strongest of all

reinforcements, are also available. Many new organic fibres have also become available lately. These include para-aramid types like Kevlar HM-50, and the polyethylene-based Spectra 900/1000. Fibres are developed on a regular basis in an effort to overcome the shortcomings of existing materials. In spite of their general use, glass fibres, for example, cannot be used as reinforcement if the materials are to be subjected to an alkaline environment because they will be highly corroded, To overcome this drawback, Pilkington has developed alkali-resistant glasses containing $\mathrm{Zr}_{2} \mathrm{O}_{3}$. Nickel-coated carbon fibre (commercially known as Vapor $\mathrm{Fab}$ ) is a family of fibres produced by a proprietary vapour -deposition process that provides for shielding against electromagnetic and radiofrequency interference when the material is used in injection moulding compounds. It is claimed that a $12 \mathrm{~K}$ tow (a tow consisting of 12000 filaments) of $7 \mu \mathrm{m}$ diameter fibre coated with 20 weight per cent nickel, when used as a 10 per cent (weight) chopped filler in polycarbonate, can provide for a shielding efficiency of $75 \mathrm{~dB}$. This is of importance in the shielding of computer, electronic, and communications equipment. This type of fibre also provides for lightweight protection against lightning strikes 
when woven into cloth and used in composite structural parts (for example, in aircraft or other types of application that need lightning protection such as fuel tanks). Connected to a heating system, a composite part, reinforced with this material can provide for effective removal of built-up ice[5].

Metallic glasses appear to be highly suitable for the reinforcement of polymers or metals. These materials, produced by rapid solidification processing of metallic alloys, are also now being used for fibre reinforcement. Typical alloys that can be treated in this way include various alloyed combinations of $\mathrm{Fe}, \mathrm{Ni}, \mathrm{Cr}$, $\mathrm{P}, \mathrm{B}, \mathrm{Si}$, and $\mathrm{C}$. One example[6] is fibre composed of $\mathrm{Fe}_{80} \mathrm{~B}_{20}$, which has exceptional corrosion resistance and a yield strength of $3.6 \mathrm{GPa}$, the latter being exceptionally high among structural materials. Although primarily developed as reinforcement for advanced composites, many fibres now start to find application as substitute materials for asbestos in ordinary commercial applications such as in the manufacture of paper, textiles, coatings, flooring, insulation, and tape.

\subsection{Composites with polymer matrices:}

\section{Composite systems and developments}

Polymer-matrix composites (PMCs) have matrices of thermoplastic or thermosetting polymerstraditionally glass fibre available in the form of rovings or woven material embedded in polyester. These materials are utilized at temperatures of not more than $200^{\circ} \mathrm{C}$ in commercial, industrial, and transportation applications, including chemically resistant piping, valves, pressure vessels, and reactors. The large numbers of resin formulations, curing agents, and fillers provide an extensive range of possible properties. Because they are superior to polyesters in resisting moisture and offer superior mechanical properties, epoxies have been the commonest thermosetting matrix material for more demanding applications. Bismaleimide resins (BMIs), on the other hand, possess many of the same desirable properties as epoxies, such as handlability, relative ease of processing, and good mechanical properties, and have service temperatures of up to $250^{\circ} \mathrm{C}$ compared with $180^{\circ} \mathrm{C}$ for epoxies. Thermosets are constantly being upgraded to tougher grades of higher heat resistance. Newly developed polyimide (PI) resins, for instance, can withstand exposure to temperatures of more than $300^{\circ} \mathrm{C}$. However, when these polymerscure, volatile matter is released, which produces undesirable voids in the final product. Although this problem has been solved,

polyimides are too brittle for very demanding applications. phenolic resins suffer the same disadvantage but are used for applications that demand relatively high heat resistance .Difficult to ignite, phenolics produce less smoke, and are less toxic when they do burn. They are therefore used for the interior panels of aircraft, where combustion requirements justify lower properties.Also, these materials and the newly developed thermoplastic polyethersulphone contain additives that react to fire by emitting contained water as vapour, which extinguishes the firell. Attempts to improve the hot-wet performance and impact resistance of thermosetting resins like epoxies and BMls are continuing. Thermoplastic matrix materials exhibit high strain to failure, and are ideally suited for use as matrix material combined with high-strength and high-strain carbon fibres. These materials include resins such as polyetheretherketone (PEEK), with a melting point of $334^{\circ} \mathrm{C}$, polyphenylene sulphide (PPS), poly etherimide (PEI), polyamideimide (PAl), and polyether sulphone (PES). In general, they have an unlimited shelf life, and offer lower-cost composite processing because they can be potentially remoulded by the application of heat and pressure. Composite thermoplastics are very different from the general commercial thermoplastics such as polyethylene, temperatures.

polyvinyl chloride and polystyrene. These thermoplastics are tougher and can withstand higher service

Experiments with a blowtorch on aluminium and a carbon fibre-PEEK composite showed that the latter withstood the flame much better .Apart from the cost aspect, the choice of a polymer for a specific application must be based on a full knowledge of the material properties required for the intended service temperatures and loads. Excellent accounts are available covering these aspects for epoxies, polyimides, bismaleimides, thermoplastic systems, and high-temperature polymers.

DuPont recently announced its thermoplastic engineered preforms (Tepex), which consists of a consolidated sheet composite that can be formed into complex parts in less than 60 seconds, avoiding labour intensive, time consuming, and costly fabrication techniques.It is reported that end-users can choose from a wide selection of resins-from low performance types to the more exotic polymers' such as PEEK-and also make a selection from different continuous fibre systems (fabrics, and unidirectional or, non-woven systems) of varying types such as glass, Kevlar, carbon, and hybrids. New grades of performance polymers increasingly appear on the market. Among the newcomers is a family of polymers based on polycyclohexylene-dimethyleneterephtalate

or PCT,which is a high-temperature, semi-crystalline, thermoplastic polyester that melts at $285^{\circ} \mathrm{C}$ and is capable of long-term service temperatures of up to $170^{\circ} \mathrm{C}$. In addition, Mitsui Toatsu Chemicals of Japan has synthesized a siliconbased polymer that is more heat-resistant than polyimide. It is known as poly [(phenylsilylene)-acetylyne phenylene acetylene], and it is reported as being sufficiently heatresistant for use in 
the intermediate walls of spacecraft and in fire-retarding materials in skyscrapers and in other refractories in severe environments. The secret of the new polymer's good refractory properties, according to the report, lies in the high bond energy of the Si-chemical links. PMCs are increasingly being employed as structural materials in civil, military, aerospace, automotive, and industrial applications where the weight reduction can contribute towards savings in fuel and other materials. Modern engines and transmissions place stringent requirements on the capability of drive shafts and couplings, such as continuous operation at high speed and high misalignment. The shaft must therefore weigh as little as possible in order to meet natural-frequency requirements. PMCs offer significant advantages over metals in such applications because of their lower weight, higher stiffness-to-weight ratio, and higher fatigue-strain capability and corrosion resistance. The use of composites in the manufacture of drive shafts is not new in that the use of glass, graphite, and hybrids in this type of application has been reported, while flexible couplings have also been made from these materials. However, the combination of shaft and couplings into a single unit is unique. Bentley-Harris Manufacturing Company of Lionville, Pennsylvania, used this concept combined with automated braiding fabrication techniques to manufacture affordable and reliable drive shafts capable of transmitting $1200 \mathrm{hp}$ in the range between 16000 and $26000 \mathrm{r} / \mathrm{min}$ at $71^{\circ} \mathrm{C}$ with 3 degrees of angular misalignment at each coupling. The braiding of prepreg fibre over tooling also allows the manufacture of net-shape parts (for example, reliable low-weight cable hoist drums capable of larger real takeups). High energy-absorbing compounds are now being used in the manufacture of bumpers and filamentwound leaf springs, replacing steel suspensions with a mass saving of 60 per cent. Composites are also increasingly being used for marine applications. This is an area where aramid fibres find wide usage. Because of its increased resistance against corrosion, rotting, and oxidation, which lead to the deterioration of mechanical properties, a PMC was chosen as the material for seawalls that act as front-line protection against shoreline erosion. These structures can be moved and assembled by individual workers using only standard tools. PMCs (reinforced with carbon fibres) are also coming into use for prosthetic purposes. It was estimated in 1988 that sports goods consume close to 30 per cent of the composite materials produced in the world.

According to Waterman, graphite-reinforced phenolic material and the modified thermoplastic acrylic resin Modar from ICI are among the more attractive materials available for mining applications because they are specially formulated to accommodate high loadings of the fire-retarding additive aluminium trihydrate. $\mathrm{He}$ suggests that phenolic graphite reinforced polymer composites would be ideal for structures such as elevated walkways, floor-support systems, racks, ladders and handrails because they can be pultruded to produce standard sections or profiles. He reports that the chemical and the offshore oil industries already use this material for flooring, and that it is also considered for use in coal mines in Europe, suggesting that these materials may also be suited to applications such as geotextiles, and liners for tailing ponds and heap-leaching pads. They can also be used for rock bolting because their flexibility allows the installation of bolts longer than the height of tunnels. It is reported that a phenolic-filament-wound graphite-fibre reinforced plastic is currently being tested for underground pipework and ducting. Studies are also under way to utilize these materials for the housings of hydraulic roof-support props, although it is expected that laminated aluminium may be better suited to this type of application because of its lighter weight. Mild sulphuric acid is sprayed over low-grade copper ore, and the leachate is collected via a series of drainage ditches into holding ponds before being processed. The associated platforms and walkways, at around half the weight of similar steel structures and therefore easier to install and float, are designed to rise and fall according to increasing or decreasing water levels. Other mining and industrial applications include glass-reinforced polymer hydro cyclones, pressure vessels, pressure-vessel safety enclosures, and abrasion-resistant components. Lightweight, ultra-strong, shock-resistant polyethylene ultra-high molecular- weight (UHMW)/Choisting cable, and lightweight tough, ergonomically-designed safety helmets, are also manufactured.

\subsection{Composites with metal matrices}

Metal-matrix composites are currently the focus of intense world-wide research and development. These materials are fabricated by liquid-infiltration techniques, such as high pressure infiltration casting, squeeze casting, vacuuminfiltration casting, compocasting, and pressureless metal infiltration. Other methods of fabrication include powdermetallurgical techniques, plasma spraying of matrix material over properly laid fibres, physical-vapour deposition, hot pressing, and self-propagating high-temperature synthesis or reactive synthesis. In addition to improved strength, stiffness, and abrasion resistance, and reduced density, MMCs are capable of providing increased oxidation resistance at high temperature operating limits. Fibre reinforcements in metal matrix materials of particular interest include carbon graphite (continuous fibre)/copper, graphite (continuous fibre)/ aluminium, $\mathrm{SiC}$ (carbon-coated discontinuous fibre, whisker and particulate)/aluminium, $\mathrm{SiC}$ (whisker and particulate)/ magnesium, and $\mathrm{SiC}$ (particulate)/magnesium. Although not precisely termed MMCs, reinforced ordered intermetallic composites, such as titanium and nickel aluminides, are becoming important because the aluminides exhibit the unusual characteristic of increased yield strength with temperature. Other 
systems include the use of graphite added to aluminium and zinc alloys to improve wear resistance by the formation of a lubricating film on the surface of the material.

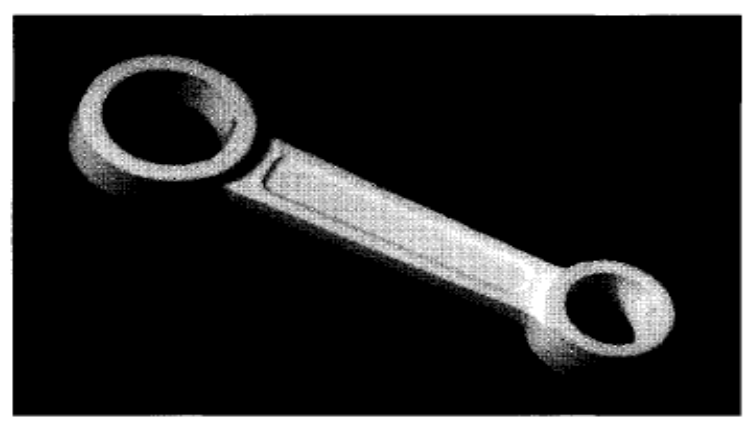

Fig.2. Example of a pre machined discontinuous two-dimensional ceramic-fibre preform ready for infiltration by a molten metal alloy in the manufacture of a composite connecting rod with a net-shaped metal matrix.

Nickel-coated carbon-fibre paper (Ashland Carboflex) has been used in the successful fabrication of aluminium based MMCs. The nickel coating not only behaves as a wetting agent, but also reacts with the molten aluminium to form hard $\mathrm{NiAb}$ and $\mathrm{NiAI}$ intermetallic compounds that contribute to superior wear resistance of the composite in dry sliding wear. Directionally-reinforced aluminium composites using $\mathrm{Al}_{2} \mathrm{O}_{3}$ and $\mathrm{SiC}$ fibres are rapidly emerging as commercial materials for improving fuel economy and recyclability in the automotive industry. An estimate of the trade-off between weight and fuel economy is that a reduction in weight of $91 \mathrm{~kg}$ increases the fuel efficiency by approximately $0.43 \mathrm{~km} /$ litre. Selective reinforcement of metals is another concept with increased appeal. It allows the designer to optimize particular properties by placing fibre performs within the component. The infiltration of these porous fibre preforms, composed of discontinuous ceramic fibres (such as $\mathrm{Al}_{2} \mathrm{O}_{3}$ or $\mathrm{Al}_{2} \mathrm{O}_{3}+\mathrm{SiO}_{2}$, commercially known as SAFFIVID and KAOWOOL respectively), orientated in a two-dimensional random plane with a metal such as aluminium by squeeze casting, produces an MMC composite with superior wear resistance, improved high-temperature strength, low thermal expansion, and increased hardness. This method of fabrication in which a fibre preform is employed can be used to solve some very difficult design problems, and has the added advantage that preforms can be premachined or fabricated to take the form of a structural part, enabling near-net shapes to be infiltrated and manufactured .SiC-whiskerzo and nickel-coated carbon-fibre perform materials are also now available.. In this low-cost approach to the manufacture of high-performance MMCs, the wetting and spontaneous infiltration of a particulate or fibre preform by a molten metal alloy are effected by a novel proprietary technique involving the use of dopant elements to raise the melt temperatures

The unique properties of MMCs (wear resistance, strength, and stiffness) have already led to more than the laboratory scale manufacture of automotive components such as brake callipers, pump housings, gears, valves, pulleys, drive shafts, brake rotors, engine blocks, connecting rods, and pistons. Systems reinforced with continuous fibres, such as aluminium tubing and sheets reinforced with $\mathrm{SiC}$ fibre, that can be used for structural applications, are also available commercially. Whereas a great deal of development has taken place with respect to the use of fibre preforms or other methods in the fabrication of tough, wear-resistant composites, there is also interest in the development of tough metal-matrix composites based on particulate iron having extraordinary wear resistance and cutting performance. The hardmetal systems at present in widespread commercial use are those based on $\mathrm{TiC}$ as reinforcement. They are produced by powder-metallurgical techniques and involve vacuum sintering. Terry and Chinyamakobvuz have demonstrated the viability of producing $\mathrm{Fe}-\mathrm{Ti}(\mathrm{O}, \mathrm{C})$ MMCsby the one-step carbothermic reduction of mixtures of iron-ilmenite $\left(\mathrm{FeTiO}_{3}\right)$ and iron-rutile $\left(\mathrm{TiO}_{2}\right)$ with coal. The processing technique, has attracted attention because of its potential for the direct conversion of raw materials to iron-based metal-matrix composites reinforced with particulate $\mathrm{TiC}$. Furthermore, it composites reinforced with particulate $\mathrm{TiC}$. Furthermore, it has been rightly claimed that this process offers the opportunity for the production of near-net shaped structures by casting techniques. Fundamental work in this field is being undertaken in an effort to produce TiC-Fe composites using South African ulv6spinel [(Fe,TihO $\left.{ }_{4}\right]$, ilmenite $\left(\mathrm{FeTiO}_{3}\right)$, and rutile $\mathrm{Z}_{4}$. Preliminary results indicate that this route is viable, and that good dispersion of $\operatorname{Ti}(\mathrm{O}, \mathrm{C})$ can be obtained in the iron matrix. The results also indicate that the primary textures of the ores must be considered and that they can be exploited for superior dispersion of the TiC.

\section{CONCLUSION}

Composites have attractive mechanical and physical properties that are now being utilized in industry and aerospace on a grand scale world-wide. New fibres, polymers, and processing techniques for all classes of composites are constantly being developed. Research is also ongoing to improve repair techniques, recyclability, and the bonding between fibres and matrix materials. Moreover, standards are being set up for the testing and 
computerization of mechanical- and corrosion-property databanks. Because of the development of new fireretarding constituents, the availability of polymers with higher temperature ratings, the relative ease of fabrication, and the fair costs, PMCs are being utilized more in structural and wear-resistant applications in mining and industrial environments. There is no doubt that, if processing costs can be substantially reduced, MMCs and CMCs will be increasingly employed in applications that require light weight in addition to toughness and wear- and abrasion-resistant properties. CMCs will increasingly be used for high-temperature, oxidation-resistant, and wear- and abrasion-resistant applications where good corrosion resistance is also required. Leading international companies involved in the traditional manufacture of metal and ceramic parts are already positioning themselves to obtain a market share. The new applications that are being found on an almost daily basis, and the continuous reporting of company investments and new ventures into the manufacture of MMC and CMC parts, tend to indicate that important progress has been made towards the reduction of processing and manufacturing costs. However, it is important to realize that the use of composites requires an integrated approach between user and designer/manufacturer to ensure functionality. This entails a knowledge of the structural efficiency of the material, its isotropic or anisotropic behaviour, environmental effects, and its manufacturing requirements, assembly, and repair.

\section{REFERENCES}

[1] F.P. Gerstle, IComposites," Encyclopedia of Polymer Science and Engineering, Wiley, New York, 1991

[2] Carter ,F.C., and Paul,D.E. Material science and engineering. Ohio, ASM International, 1991351 pp.

[3] Ashby, M.F., and Jones,D.R.H. Engineering materials-an introduction to their properties and applications. Oxford, pergamon Press, 1985. 277 pp.

[4] HarrisS,B. A perspective view of composite materials. Mat \& Design, vol 12, no. 5. 1991. pp. 259-271.

[5] Materials Edge, no. 50. Ju!. 1993, p. 4

[6] PIGLIACAMPJI.,J. Organic fibers. Engineering materials handbook 1, Composites. Dostal, c.A., et al. (eds.). Ohio, A.S.M. International, $1989.983 \mathrm{pp}$. 